Original

\title{
Development of Apoptosis and Changes in Apoptosis-Related Genes Expression in the Thymus of Nivalenol-Treated Mice
}

\author{
Amnart Poapolathep ${ }^{1}$, Kazuhiko Suzuki ${ }^{1}$, Kei-ichi Katayama ${ }^{1}$, Ryoichi Ohtsuka ${ }^{1}$, \\ Takayuki Nagata ${ }^{1}$, Koji Uetsuka ${ }^{1}$, Hiroyuki Nakayama ${ }^{1}$, and Kunio Doi ${ }^{1}$ \\ ${ }^{1}$ Department of Veterinary Pathology, Graduate School of Agricultural and Life Sciences, The University of Tokyo, \\ 1-1-1 Yayoi, Bunkyo-ku, Tokyo 113-8657, Japan
}

\begin{abstract}
Nivalenol (NIV) is a potent toxic trichothecene mycotoxin produced by Fusarium nivale, and our previous study clarified first that NIV induces apoptosis in lymphoid organs of mice in a dose-dependent manner. In this study, the development of apoptosis and changes in the expression of apoptosis-related genes (fas, c-fos, $c$-jun, p53, bcl-2 and $c-m y c)$ mRNAs were examined in the thymus of mice for up to 12 hours after inoculation (HAI) of NIV (15 mg/kg b.w.) to elucidate the relationship between the molecular genetic regulatory mechanisms and NIV-induced lymphocyte apoptosis. The number of apoptotic lymphocytes evaluated by TUNEL method clearly increased from 3 HAI and peaked at 9 HAI. The DNA ladder formation by agarose gel electrophoresis was clearly observed at 6 and 9 HAI. The expression of $c$-fos and $c$-jun mRNAs clearly elevated from $0.5 \mathrm{HAI}$ and peaked at 1 HAI. The expression of fas, $p 53$, $b c l-2$ and $c$-myc mRNAs showed no significant changes. These results indicate that $c$-fos and $c$-jun may play an important role in NIV- induced lymphocyte apoptosis. (J Toxicol Pathol 2001; 14: 299-304)
\end{abstract}

Key words: Nivalenol, mouse, thymus, apoptosis, apoptosis-related genes

\section{Introduction}

Nivalenol (NIV) is a kind of type B trichothecene mycotoxins produced by many species of Fusarium. Contamination of agricultural products by trichothecene mycotoxins is occurring worldwide, and spontaneous outbreaks of Fusarium mycotoxicoses, especially due to deoxynivalenol (DON) and Nivalenol (NIV), have been regularly reported throughout the world ${ }^{1}$. In our previous study, we clarified from the multiple viewpoints that NIV induces apoptotic cell death in lymphoid organs in a dosedependent manner ${ }^{2}$. The pathways by which apoptosis is induced vary depending on stimulators and cell types, and it is well known that some proto-oncogenes called apoptosisrelated genes regulate the induction and/or inhibition of apoptosis $^{3-5}$.

In this study, the development of apoptosis and the sequential changes in the expression of apoptosis- related genes (fas, c-fos, $c$-jun, p53, bcl-2 and c-myc) mRNAs were investigated in order to elucidate the relationship between the molecular genetic regulatory mechanisms and NIV-

Received: 3 August 2001, Accepted: 29 November 2001 Mailing address: Amnart Poapolathep, Department of Veterinary Pathology, Graduate School of Agricultural and Life Sciences, The University of Tokyo, 1-1-1 Yayoi, Bukyo-ku, Tokyo 113-8657, Japan TEL: 81-3-5841-5401 FAX: 81-3-5841-8185

E-mail: fvetamp@hotmail.com induced lymphocyte apoptosis in the thymus of mice.

\section{Materials and Methods}

\section{Animals}

Forty-five 4-week-old male ICR:CD1 mice were purchased from Charles River Japan Inc. (Kanagawa, Japan) and acclimatized to the environment for 1 week. They were kept in an air-conditioned animal room (temperature: $23 \pm$ $2{ }^{\circ} \mathrm{C}$; humidity: $55 \pm 5 \%$ ) with a $12 \mathrm{~h}$-light/ $12 \mathrm{~h}$-dark cycle and fed commercial pellets (MF, Oriental Yeast Co., Ltd., Tokyo) and water ad libitum throughout the experimental period.

\section{Chemicals}

Nivalenol (NIV, lot no. KSE7430) was purchased from Wako Pure Chemical Industries Ltd. (Kyoto, Japan), and it was dissolved with $10 \%$ dimethyl sulfloxide (DMSO, Wako Pure Chemical Industries Ltd.) in physiologic saline to the final concentration of $1 \mathrm{mg} / \mathrm{ml}$ for oral administration.

\section{Treatments}

After overnight fasting, 40 5-week-old male ICR:CD1 mice (body weight: $28.3 \pm 1.4 \mathrm{~g}$ ) were orally administered with NIV at the dose level of $15 \mathrm{mg} / \mathrm{kg}$ body weight. The dose of NIV was determined based on the results of the previous study ${ }^{2}$. Five mice were sacrificed by heart puncture under ether anesthesia at $0.5,1,2,3,4,6,9$ and 12 hours 
after inoculation (HAI), respectively. In addition, the remaining 5 mice which were inoculated with $10 \%$ DMSO in physiologic saline in the same way and killed at 12 HAI served as controls.

The present study was approved by The Laboratory Animal Use and Care Committee of Graduate School of Agricultural and Life Sciences, The University of Tokyo.

\section{Histology}

At necropsy, the thymus was taken from each mouse, and fixed in $10 \%$ neutral buffered formalin. Paraffin sections $(4 \mu \mathrm{m})$ were stained with hematoxilin and eosin (HE). For electron microscopic examination, small pieces of the thymus were fixed in $2.5 \%$ glutaraldehyde in $0.1 \mathrm{M}$ phosphate buffer ( $\mathrm{pH} 7.4$ ), post-fixed in $1 \%$ osmium tetroxide in the same buffer, and embedded in Epok 812 (Ohken Co., Ltd., Tokyo). Ultrathin sections were double stained with uranyl acetate and lead citrate and observed under a JEM-1200 EX electron microscope (JEOL Co., Ltd., Tokyo). Some of paraffin sections were subjected to in situ detection of fragmented DNA as mentioned below. In addition, a part of the fresh thymus was stored at $-80^{\circ} \mathrm{C}$ until used for agarose gel electrophoresis and reverse transcriptase-polymerase chain reaction (RT-PCR).

\section{In situ detection of fragmented DNA}

In situ detection of fragmented DNA was carried out on the paraffin sections of thymus by the modified TUNEL method first proposed by Gavrieli et al. ${ }^{6}$ using a commercial apoptosis detection kit (Apopotag In situ Apoptosis Detection Kit; Intergen Co.). In brief, the procedure was as follows: multiple fragmented DNA 3'-OH ends on the paraffin sections were labeled with digoxygenin-dUTP in the presence of terminal deoxynucleotidyl transferase (TdT). Peroxidase-conjugated anti-digoxygenin antibody was then reacted with the sections. Apoptotic nuclei were visualized by peroxidase-diaminobenzidine (DAB) reaction. Counterstain was performed with methyl green. The TUNEL index (\%) (positive cells / 1,000 lymphocytes $\times$ 100) was calculated on each section.

Agarose gel electrophoresis for the detection of DNA ladder formation

Dneasy Tissue Kit (QIAGEN GmbH, Germany) was used for DNA extraction from the frozen thymus samples.
Each sample was placed in a $1.5 \mathrm{ml}$ microcentrifuge tube with lysis buffer and proteinase $\mathrm{K}$ and incubated at $55^{\circ} \mathrm{C}$ until being completely dissolved. Then, it was added with $\mathrm{AL}$ buffer and $\mathrm{EtOH}$, and the lysate in a spin column was centrifuged at $8000 \mathrm{rpm}$ for $1 \mathrm{~min}$. After being washed with AW buffer and centrifuged, spin column was placed in a clean $1.5 \mathrm{ml}$ collection microtube and then DNA was eluted in microtubes with TE buffer preheated to $70^{\circ} \mathrm{C}$. The eluate was used as DNA sample for agarose gel electrophoresis.

DNA samples were electrophoretically separated on $2 \%$ agarose in Tris boric acid-EDTA solution (TBE), Tris base, boric acid and 0.5 M EDTA ( $\mathrm{pH} \mathrm{8.0).} \mathrm{After}$ electrophoresis, gels were stained with $0.5 \mu \mathrm{g} / \mathrm{ml}$ of ethidium bromide (Sigma Chemical Co.) for $20 \mathrm{~min}$, visualized with a UV light $(312 \mathrm{~nm})$ transilluminator, and photographed with VIDEO Graphic Printer UP-880.

\section{Reverse transcriptase-polymerase chain reaction (RT- PCR)}

The total RNA was extracted from the thymus homogenate of each mouse using Isogen (Nippon Gene Co. Ltd., Toyama, Japan). Reverse transcriptase (RT) reaction for the first strand cDNA synthesis was carried out using oligo $(\mathrm{dT})_{12-18}$ primer and SUPERSCRIPT Preamplification System (GibcoBRL, Life technology Co., USA). Polymerase chain reaction (PCR) was performed with pairs of oligonucleotide primers corresponding to the cDNA sequences of mouse mRNA (Table 1). PCR was carried out in a $50 \mu \mathrm{l}$ reaction mixture containing $50 \mathrm{pM}$ of sense and antisense primer, $1.25 \mathrm{U}$ ampliTaq Gold ${ }^{\mathrm{TM}}, 10 \times \mathrm{PCR}$ buffer, and dNTP mixture (Perkin Elmer, NJ., USA). This was immediately followed by pre-heating at $95^{\circ} \mathrm{C}$ for $7 \mathrm{~min}$, denaturation at $94^{\circ} \mathrm{C}$ for $1 \mathrm{~min}$, annealing for $1 \mathrm{~min}$ and extension at $72^{\circ} \mathrm{C}$ for 1 min using Takara PCR Thermal Cycler MP (Takara, Ohtsu, Japan). Annealing temperature and cycle number are shown in Table 1 . PCR products were identified by electrophoresis on $2 \%$ agarose gel (Nippon Gene Co., Ltd., Toyama, Japan) followed by ethidium bromide (Sigma Chemical Co.) staining. Fluorescence image of gel was visualized under a UV-CCD video system (Epi-Light UV $\mathrm{VV}_{\mathrm{FA1} 100}$; AISIN COSMOS R \& D Co., LTD., Tokyo) and the data were fed into a computer. The image was analyzed using a Luminous Imager software (AISIN COSMOS R \& D Co., Ltd., Tokyo). The average of 5 mice was calculated, and the results were shown as a relative ratio

Table 1. Primer Sequences, Annealing Temperature (Tm) and Cycle Numbers

\begin{tabular}{|c|c|c|c|c|}
\hline & Sense primer & Antisense primer & $\mathrm{Tm}$ & Cycle No \\
\hline Fas & GCTGGCTCACAGTTAAGAGTTC & TGCACTTGGTATTCTGGGTCAG & 54 & 29 \\
\hline$c-f o s$ & AATGGTGAAGACCGTGTCAGG & GTTGCTGATGCTCTTGACTGG & 58 & 31 \\
\hline$c-j u n$ & GATGGAAACGACCTTCTACGAC & ACGTTCTTGGGGCACAAGAACT & 58 & 31 \\
\hline$c-m y c$ & CСTATTTCATCTGCGACGAGGA & TGGTTCACCATGTCTCCTCCAA & 52 & 30 \\
\hline p53 & AGCCAGGAGACATTTTCAGGCT & AAGCCATAGTTGCCCTGGTAAG & 53 & 28 \\
\hline$b c l-2$ & AGAACAGGGTATGATAACCGGG & ACATGACCCCACCGAACTCAAA & 54 & 29 \\
\hline GAPDH & TGAAGGTCGGTGTGAACGGATTTGGC & CATGTAGGCCATGAGGTCCACCAC & 59 & 22 \\
\hline
\end{tabular}


to glyceraldehyde-3-phosphate dehydrogenase (GAPDH) expression.

\section{Statistical analysis}

The results of TUNEL index and mRNA expression levels were shown as mean \pm standard deviation (SD) of 5 mice. Statistical analysis was performed using the Student's or Welch's t-test.

\section{Results}

\section{Histological and electron microscopical findings}

In the thymus of NIV-group, a small number of lymphocytes showing pyknosis or karyorrhexis were found in the cortex from 0.5 to $2 \mathrm{HAI}$. The number of such lymphocytes clearly increased at $3 \mathrm{HAI}$ and peaked at $9 \mathrm{HAI}$ (Fig. 1). No inflammatory reactions were detected in the thymus until $12 \mathrm{HAI}$.

In electron microscopic examination, the number of cortical lymphocytes characterized by shrinkage of cell body, condensation of nuclear chromatin and/or margination of condensed chromatin along the nuclear membrane increased at $3 \mathrm{HAI}$ (Fig. 2). Later, many cell nuclei were fragmented into small pieces, some of which were ingested by adjacent epithelial cells and macrophages (Fig. 3).

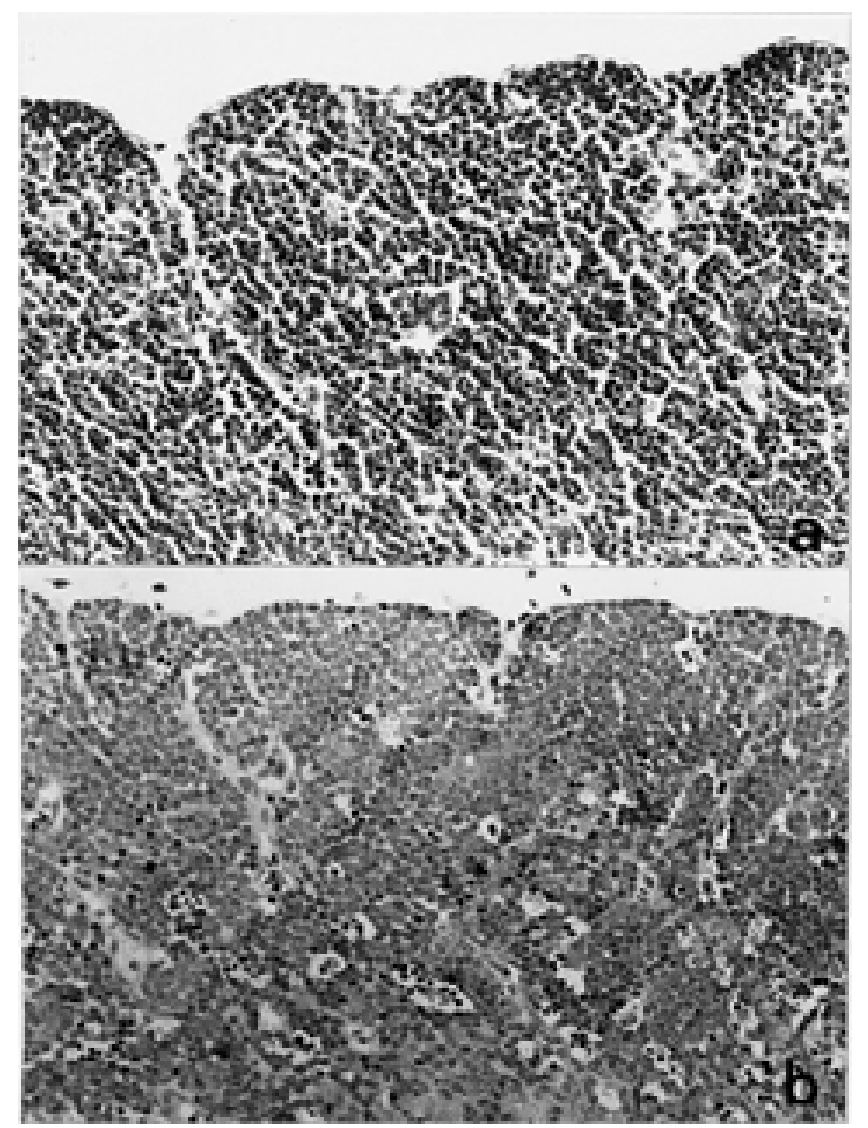

Fig. 1. Thymic cortex of a control mouse (a) and a NIV-inoculated one at 9 HAI (b). Compared with (a), many pyknotic or karyorrhectic lymphocytes are seen in (b). HE $\times 200$.
Findings of in situ detection of fragmented DNA

In the thymic cortex, almost all of the nuclei of lymphocytes which showed pyknosis or karyorrhexis were stained by the modified TUNEL method (Fig. 4), and the TUNEL index clearly increased at $3 \mathrm{HAI}$, and peaked at 9 HAI (Fig. 5).

\section{Findings of agarose gel electrophoresis}

The DNA ladder formation was not detected at $3 \mathrm{HAI}$, but it was clearly observed at 6 and 9 HAI (Fig. 6).

\section{Expression of apoptosis-related genes $m R N A s$}

The levels of $c$-fos and $c$-jun mRNAs were significantly

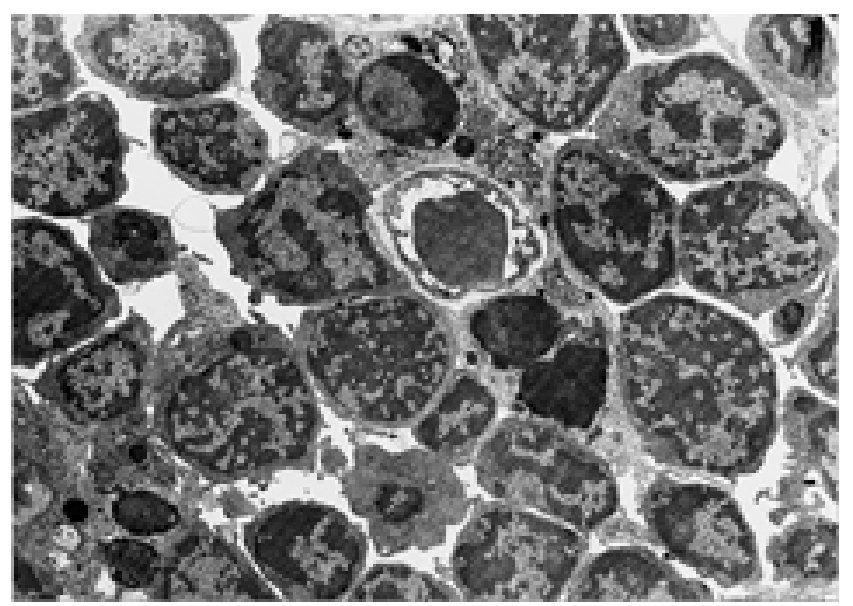

Fig. 2. Thymic cortex of a NIV-inoculated mouse at 3 HAI. Lymphocytes showing nuclear chromatin condensation and/ or margination of condensed chromatin along the nuclear membrane are seen. $\times 2600$.

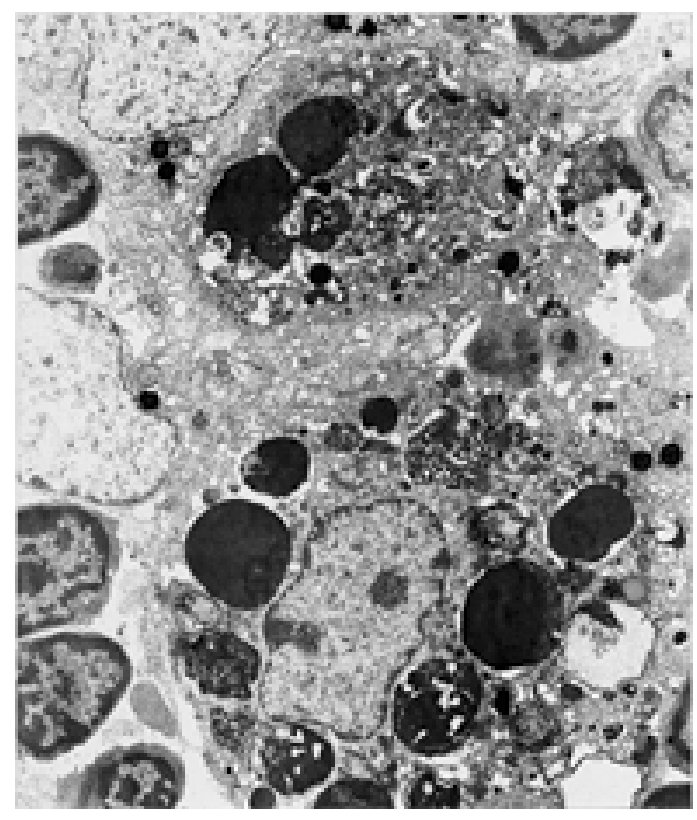

Fig. 3. Thymic cortex of a NIV-inoculated mouse at 9 HAI. Many apoptotic bodies are ingested by epithelial cells. $\times 4000$. 


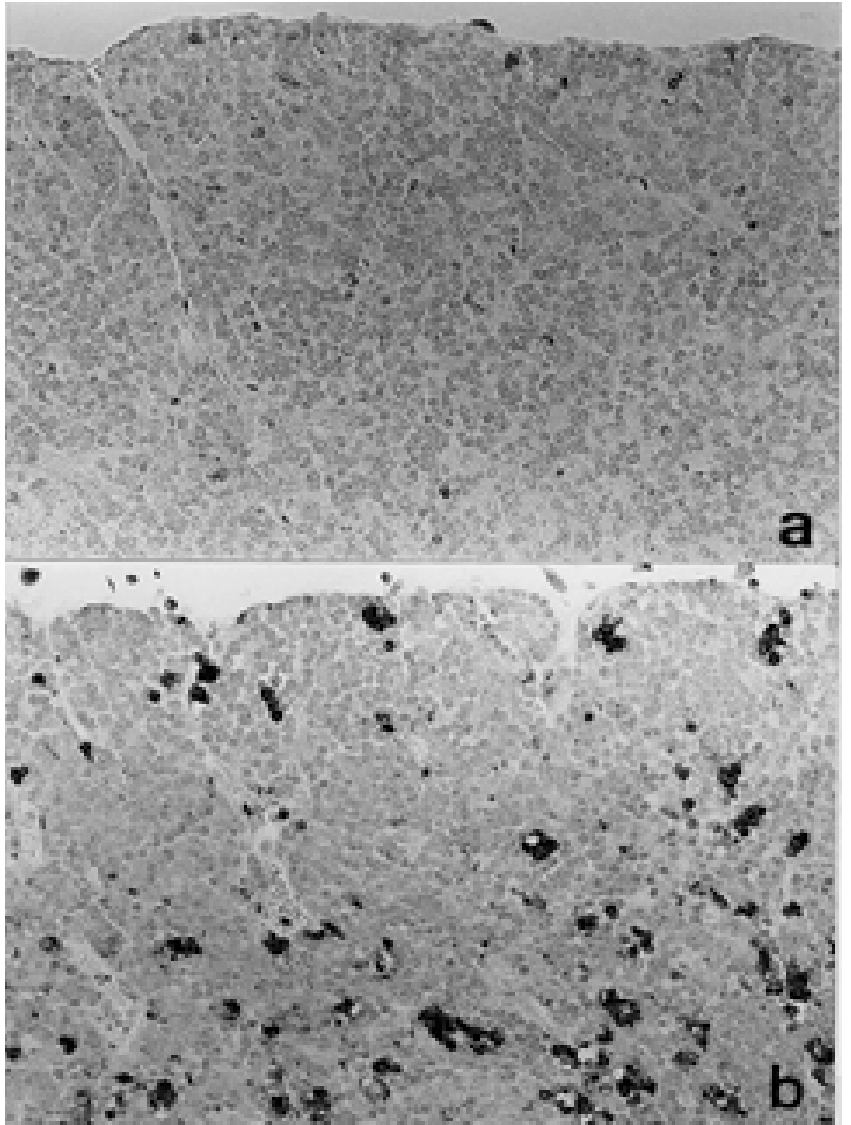

Fig. 4. Thymic cortex of control mouse (a) and a NIV-inoculated one at 9 HAI (b). Only a few TUNEL-positive lymphocytes are seen in (a) while many TUNEL-positive ones are seen in (b). TUNEL-staining. $\times 200$.

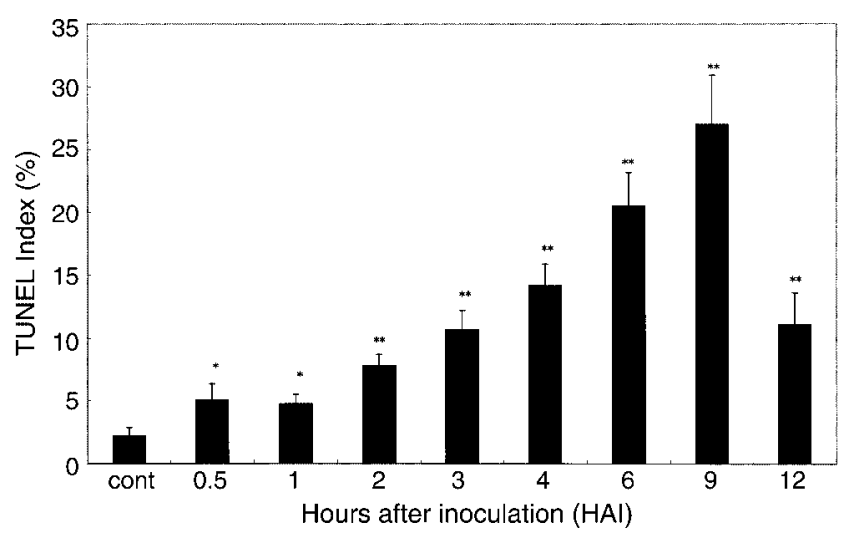

Fig. 5. Changes in TUNEL-index in the thymus after NIVinoculation. Each value represents mean \pm SD of 5 mice. $(*)$, $\mathrm{p}<0.05,(* *), \mathrm{p}<0.01$ : Significantly different from controls.

elevated at $0.5 \mathrm{HAI}$, peaked at $1 \mathrm{HAI}$, and decreased thereafter (Figs. 7 and 8). On the other hand, there were no significant changes in the expression of fas, p53, bcl-2 and $c-m y c$ mRNAs throughout the observation period (Figs. 7 and 8).

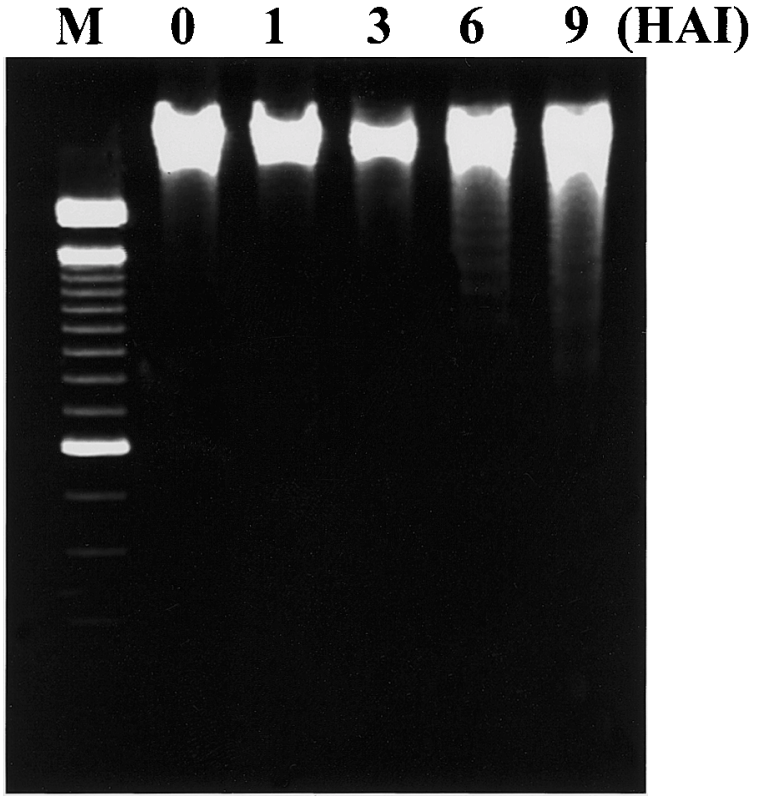

Fig. 6. Agarose gel electrophoresis of DNA extracted from the thymus of NIV-inoculated mice. Ladder formations is clearly observed at 6 HAI (lane 5) and 9 HAI (lane 6).

\section{Discussion}

As mentioned earlier, our previous study clarified that NIV is able to induce apoptosis in lymphoid organs in a dose-dependent manner ${ }^{2}$. In the present study, we examined the development of lymphocyte apoptosis and the changes in the levels of apoptosis-related genes mRNAs in the thymus of mice following NIV-inoculation, because we thought that the induction of genes coding transcriptional factors may participate in NIV-induced lymphocyte apoptosis.

As a result, TUNEL-positive thymic cortical lymphocytes clearly increased from 3 HAI and peaked at 9 HAI, and distinct DNA ladder formation was observed at 6 and 9 HAI by agarose gel electrophoresis. In addition, thymic cortical lymphocytes showed ultrastructural pictures characteristic for apoptotic cells. Moreover, there were no inflammatory reactions in the thymus. These findings suggest that at least the majority of TUNEL-positive lymphocytes are apoptotic ones in the present study, although some investigators have recently demonstrated that the TUNEL-technique is not specific for apoptic cell death ${ }^{7}$.

Activator protein-1 (AP-1) was first identified as a transcriptional factor that binds to an essential cis-element of human metallothionein IIa (hMTIIa) promotor $^{8}$ which is a protein complex containing the products of $c$-jun and $c$-fos proto-oncogenes ${ }^{9,10}$. The AP-1 transcription factor complex may play a role in switching between the cell death pathway and the cell cycle ${ }^{11}$. In addition, these proto-oncogenes are rapidly activated by a large series of signals in proliferation, differentiation and functional activation which are especially regulated by intracellular second messenger systems such as calcium mobilization and protein kinase-C activation ${ }^{12}$. 


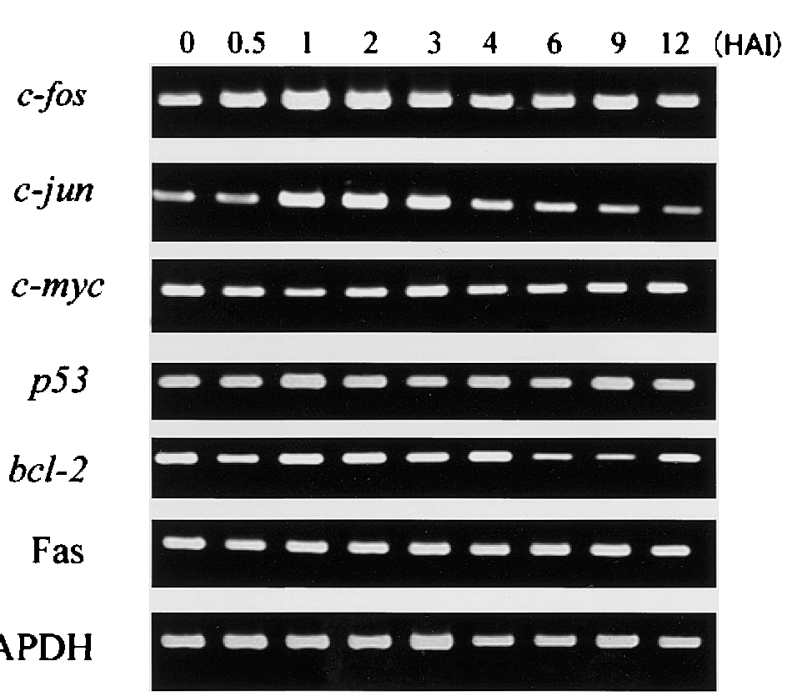

Fig. 7. Sequential changes in the apoptosis-related genes mRNAs expression from controls.

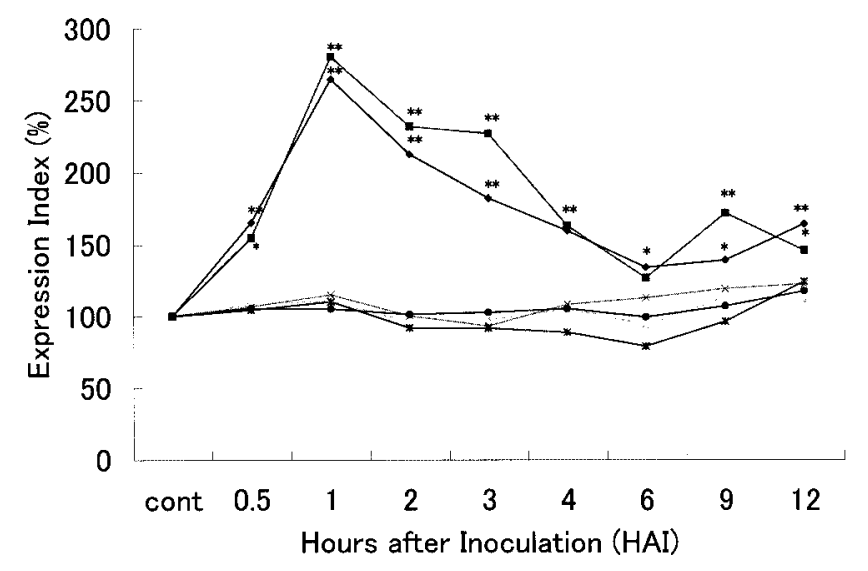

Fig. 8. Sequential changes in the apoptosis-related genes mRNAs expression in the thymus of mice following NIV-inoculation.

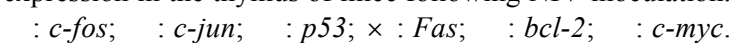
Each value represents mean $\pm \mathrm{SD}$ of 5 mice. $\left(^{*}\right), \mathrm{p}<0.05$, $(* *), \mathrm{p}<0.01$ : Significantly different from controls.

The activation of specific genes including immediateearly response genes such as $c$-fos, $c$-jun and $c$-myc is also one of the early responses to acute cell injury ${ }^{13}$. Some studies reported that the expression of $c$-fos precedes the initiation of apoptosis and it also concomitants with apoptosis in various systems ${ }^{14-16}$. Moreover, the $c$-fos and $c$ jun could be induced in the very early phase of apoptosis in hematopoietic cells after growth factor deprivation, and blocking of these sequences by antisense oligonucleotides could prevent cell death ${ }^{17}$. These findings also suggest that the induction of $c$-fos and $c$-jun may play an important regulatory role in the process of apoptosis ${ }^{17}$.

Gene induction during apoptosis has been investigated in the lymphoid tissues, and it has been clarified that some cell surface antigens and proto-oncogenes regulate the induction of apoptosis. Fas antigen, a cell-surface antigen, is also reported to be related to the negative selection (clonal deletion) and elimination of $\mathrm{CD} 4^{+} \mathrm{CD}^{+} \mathrm{T}$ lymphocytes by apoptosis through combining with Fas ligand ${ }^{18}$. The $p 53$ expression is also reported in apoptosis induction in lymphocytes and other cells by radiation and carcinostatics $^{5,19}$. It was found that expression of $p 53$ could inhibit the neoplastic transformation of primary culture cells ${ }^{20}$. Interestingly, it is reported that $b c l-2$ is a novel oncogene which promotes cell survival rather than proliferation, and its primary role in human follicular lymphoma appears to enable the cells which have acquired a 14,18 translocation to resist apoptosis in the lymphoid germinal center ${ }^{21}$. On the other hand, myc induces apoptosis of myeloid 22 and fibroblastic cell lines ${ }^{4}$. In addition, it was found that $m y c$ expression was induced by a heat shock promotor $^{23}$.

In the present study, the expression of $c$-fos and $c$-jun mRNAs prominently elevated prior to the clear development of cortical lymphocyte apoptosis following NIV-inoculation to mice. On the other hand, the expression of fas, p53, bcl-2 and $c$-myc mRNAs showed no significant changes. Similar findings were also reported by our research group in T-2 toxin-induced lymphocyte apoptosis ${ }^{16}$ and epidermal basal cell apoptosis ${ }^{24}$.

In conclusion, the present results indicate that the expression of $c$-fos and $c$-jun mRNAs may represent an important early event in the activation of genetic program of lymphocyte apoptosis by NIV.

\section{References}

1. Placinta CM, D'Mello JPF, and Macdonald AMC. A review of worldwide contamination of cereal grains and animal feed with Fusarium mycotoxins. Anim Feed Sci Technol 1999; 78: 21-37.

2. Poapolathep A, Ohtsuka R, Kiatipattanasakul W, Ishigami $\mathrm{N}$, Nakayama H, and Doi K. Nivalenol-induced apoptosis in thymus, spleen and Peyer's patch of mice. Exp Toxicol Pathol 2001; 53: in press.

3. Sentman CL, Shutter JR, Hockenbery D, Kanakawa O, and Korsmeyer SL. bcl-2 inhibits multiple forms of apoptosis but not negative selection in thymocytes. Cell 1991; 67: 879888.

4. Evan GI, Wyllie AH, Gilbert CS, Littlewood TD, Land H, Brooks M, Waters CM, Penn LZ, and Hancock DC. Induction of apoptosis in fibroblasts by c-myc protein. Cell 1992; 69: 119-128.

5. Clarke AR, Purdie CA, Harrison DJ, Morris RG, Bird CC, Hooper ML, and Wyllie AH. Thymocyte apoptosis induced by p53-dependent and independent pathways. Nature 1993; 362: 849-852.

6. Gavrieli Y, Sherman Y, and Ben-Sassan SA. Identification of programmed cell death in situ via specific labeling of nuclear DNA fragmentation. J Cell Biol 1992; 119: 493501.

7. De Torres C, Munell F, Ferrer I, Reventos J, and Macaya A. Identification of necrotic cell death by the TUNEL assay in 
the hypoxic ischemic neonatal rat brain. Neurosci Lett 1997; 230: $1-4$.

8. Lee W, Haslinger A, Karin M, and Tjian R. Activation of transcription by two factors that bind promoter and enhancer sequences of the human metallothionein gene and SV40. Nature 1987; 325: 368-372.

9. Angel P, Allegretto EA, Okino ST, Hattori K, Boyle WJ, Hunter T, and Karin M. Oncogene jun encodes a sequencespecific trans-activator similar to AP-1. Nature 1988; 332: 166-171.

10. Franza BR, Rauscher FJ, Josephs SF, and Curran T. The fos complex and fos-related antigens recognize sequence elements that contain AP-1 binding sites. Science 1988; 239: $1150-1153$.

11. Riabowol K, Schiff J, and Gilman MZ. Transcription factor AP-1 activity is required for initiation of DNA synthesis and is lost during cellular aging. Proc Natl Acad Sci 1992; 89: $157-161$.

12. Carr FE, Fisher CU, Fein HG, and Smallridge RC. Thyroprotein-releasing hormone stimulates $c$-jun and $c$-fos messenger ribonucleic acid levels: Implication for calcium mobilization and protein kinase-C activation. Endocrinology 1993; 133: 1700-1707.

13. Lau LF, and Nathans D. Expression of a set of growthrelated immediately early genes in BALB/c $3 \mathrm{~T} 3$ cells: coordinate regulation with $c$-fos or $c-m y c$. Proc Natl Acad Sci 1987; 84: 1182-1186.

14. Smeyne RJ, Vendrell M, Hayward M, Baker SJ, Miao GG, Schiling K, Robertson LM, Curran T, and Morgan JI. Continuous $c$-fos expression precedes programmed cell death in vivo. Nature 1993; 363: 166-169.

15. Mils V, Piette J, Barette C, Veyrune J, Tesniere A, Escot C, Guilhou JJ, and Basset-Seguin N. The proto-oncogene $c-f o s$ increases the sensitivity of keratinocytes to apoptosis. Oncogene 1997; 14: 1555-1561.
16. Shinozuka J, Tsutsui S, Ishigami N, Ueno-Yamanouchi A, Nakayama H, and Doi K. Development of apoptosis and changes in apoptosis- related genes expression in the mouse thymus following T-2 toxin-inoculation. J Toxicol Pathol 1999; 12: 77-81.

17. Colotta F, Polentarutti N, Sironi M, and Mantovani A. Expression and involvement of $c$-fos and $c-j u n$ protooncogenes in programmed cell death induced by growth factor deprivation in lymphoid cell lines. J Biol Chem 1992; 267: 18278-18283.

18. Yonehara S. Involvement of apoptosis antigen Fas in clonal deletion of human lymphocytes induced by superantigen. Int Immunol 1994; 6: 1849-1856.

19. Lowe SW, Ruley HE, Jacks T, and Housman DE. p53dependent apoptosis modulates the cytotoxicity of anticancer agents. Cell 1993; 74: 957-967.

20. Finlay CA, Hinds PW, and Levine AJ. The p53 protooncogene can act as a suppressor of transformation. Cell 1989; 57: 1083-1093.

21. Lavin M, and Watters D. The $b c l-2$ oncogene regulates lymphocyte survival and potentiates lymphomagenesis. In:Programmed Cell Death, Harwood Acardemic Publishers GmbH, Netherlands, 167-178, 1993.

22. Askew DS, Ashman RA, Simmons BC, and Cleveland JL. Constitutive c-myc expression in an IL-3-dependent myeloid cell line suppresses cell cycle arrest and accelerates apoptosis. Oncogene 1991; 6: 1915-1922.

23. Wurm FM, Gwinn KA, and Kingston RE. Inducible overproduction of the mouse c-myc protein in mammalian cells. Proc Natl Acad Sci 1986; 83: 5414-5418.

24. Albarenque SM, Suzuki K, Shinozuka J, Nakayama H, and Doi K. Kinetics of apoptosis-related genes mRNA expression in the dorsal skin of hypotrichotic WBN/ILA- $H t$ rats after topical application of T-2 toxin. Exp Toxicol Pathol 2001; 52: 553-556. 